\title{
Retinal blood flow indices in patients infected with human immunodeficiency virus
}

\author{
Chi-Wah Yung, Alon Harris, Stephen Massicotte, George Chioran, Gabriel Krombach, \\ Ronald Danis, Sebastian Wolf
}

\begin{abstract}
Aims/background-Abnormal blood flow dynamics are believed to contribute to the development of retinal microvascular disease in patients infected with human immunodeficiency virus (HIV). In this study, the scanning laser ophthalmoscope (SLO) was used, combined with fluorescein angiography, to measure retinal blood flow indices in HIV seropositive patients.

Methods-Arteriovenous passage time (AVP) and perifoveal capillary blood How velocity (CFV) were measured in 23 HIV infected patients and 23 control subjects with SLO fluorescein angiography.

Results-No significant difference in AVP was found between the two groups. However, CFV was significantly reduced in HIV infected patients $(p=0.013)$.

Conclusion-Patients infected with HIV show abnormal haemodynamics at the level of the perifoveal capillaries.

(Br f Ophthalmol 1996;80:723-727)
\end{abstract}

Ocular lesions are a common feature of human immunodeficiency virus (HIV) infection and AIDS, having been documented clinically by a number of investigators. ${ }^{1-5}$ The most common lesions are cotton wool spots and retinal haemorrhages. These have been noted to occur in $50 \%-70 \%$ of patients with AIDS and in up to $1.5 \%$ of patients who are seropositive for HIV infection. ${ }^{2-8}$ Cotton wool spots in HIV infection and AIDS are transient and usually resolve over a period of a few weeks to a few months. ${ }^{1256}$ They are typical nerve fibre layer infarcts, found in the posterior pole, distributed near the large retinal vessels. ${ }^{4}$ They are sometimes associated with small superficial retinal haemorrhages. However, they differ from cotton wool spots found in other retinal vascular diseases, such as diabetic and hypertensive retinopathy, in that the retinal vasculature is grossly normal clinically and exudates are usually not found. HIV related retinopathy can thus be characterised by the presence of cotton wool spots, intraretinal haemorrhages, microaneurysms, or other capillary changes in a patient with HIV infection.

The aetiology of these apparently vasoocclusive phenomena in HIV related retinopathy has not been well defined. Several theories have been postulated including infectious damage of retinal vasculature and/or adjacent retinal tissue, ${ }^{9-11}$ abnormality of blood elements, ${ }^{2612-14}$ and disturbance of haemody- namics. ${ }^{15}$ However, to our knowledge, no quantification of ocular haemodynamics in HIV positive patients has been reported.

This study measured, in a quantitative fashion, several variables of the retinal circulation in HIV positive patients, using fluorescein angiography and the scanning laser ophthalmoscope (SLO), in order to determine if an alteration of retinal blood flow occurs during the course of HIV infection. The use of SLO angiography is an effective method of quantifying retinal microcirculation flow factors and has been used in a similar fashion to study diabetic patients. ${ }^{16}$ In the current study, we measured the arteriovenous passage time (AVP) and perifoveal capillary blood flow velocity (CFV) in HIV positive patients who had no clinical evidence of infectious retinopathy, and compared the data with those obtained from age-matched control subjects.

\section{Methods and materials}

PATIENT SELECTION

Patients were recruited from the Ophthalmology Service at Indiana University Medical Center. All patients were known to be HIV seropositive. Biomicroscopy and indirect ophthalmoscopy were performed on all patients, and those with no clinical signs of infectious retinopathy in at least one eye were invited to participate. Eyes that were affected by other diseases, such as glaucoma, diabetic retinopathy, or previous retinal infections were excluded from this study. In addition, patients having concurrent systemic diseases which might affect the retinal circulation, such as hypertension and diabetes mellitus, were also excluded from the study. Finally, patients with haemophilia or those who had a history of intravenous drug use were excluded.

A total of 23 patients (23 eyes) met the inclusion criteria and agreed to participate. An equal number of age-matched normal subjects served as the control group. Eyes that were entered into this study were chosen at random, with the exception of three patients who had cytomegalovirus (CMV) retinitis in one eye. In these three patients, the eye without CMV retinitis was studied. All patients and control subjects then underwent a complete eye examination which included documentation of the Snellen visual acuity, refraction, slit-lamp biomicroscopy, Goldmann applanation tonometry, keratometry, axial length measurement using A-scan ultrasonography, and dilated fundus examination. Biomicroscopic ophthalmoscopy with a +90 double aspheric 
lens and indirect ophthalmoscopy with a +20 double aspheric lens were employed to examine the fundus. Video fluorescein angiography with the SLO was performed in one eye of each patient and control subject. Angiograms were then analysed by one of us (GK) who was masked to the condition of the patient.

\section{SCANNING LASER ANGIOGRAPHY}

The Rodenstock 101 scanning laser ophthalmoscope was used according to the measuring technique presented in detail elsewhere. ${ }^{16}$ Briefly, a total of $5 \mathrm{ml}$ of $10 \%$ sodium fluorescein was injected as a bolus into an antecubital vein and was followed by a saline flush. Video images of the retinal circulation were recorded on standard high resolution videotape at 60 frames per second. The video fluorescein angiograms were then digitised and analysed offline by means of a digital image analysis system (IBAS, Kontrom, Munich, Germany). Two variables of the retinal circulation were measured: (1) the arteriovenous passage time (AVP), defined here as the time between the appearance of the dye at the disc margin in the superotemporal retinal artery and its subsequent appearance in the superotemporal retinal vein at the disc margin, and (2) the capillary blood flow velocity (CFV) in the perifoveal network, defined as the fluorescein transit time between two established reference points separated by a known distance in a given capillary vessel. The CFV is calculated offline by frame to frame analysis. At least 15 perifoveal vessels in each subject were used to determine the capillary blood flow velocity. Segments of high and low fluorescence moving through the perifoveal capillary network were observable within each vessel. The velocities of 10 segments of hypofluorescence were calculated. Therefore, every reported value of the capillary blood flow velocity is the mean of 150 measurements. In addition, the coefficent of variation for blood flow velocity, $\mathrm{CV}(\mathrm{v})$, which reflects the homogeneity of the perifoveal CFV in each patient, was also calculated from these measurements. All data were corrected for magnification using the A-scan biometry results and keratometry readings according to the Littmann formula. ${ }^{17}$

Statistical analysis of the data from the two groups of subjects consisted of the independent $t$ test, with an error probability value of less than 0.05 considered to be statistically significant. One way ANOVA test was used to further compare results between the HIV related retinopathy positive group, the retinopathy negative group, and normal controls.

\section{Results}

A total of $23 \mathrm{HIV}$ seropositive patients (23 eyes, 17 right and six left) and 23 age-matched control subjects ( 23 eyes, 15 right and eight left) were entered into the study. In each group, all but two of the 23 were males. The mean age of the patient group was 35.9 years and the mean age of the control subjects was 37 years $(p=0.642)$ (Table 1$)$. Twenty patients $(87 \%)$ were receiving systemic antiretroviral medication at the time of the study. The mean time
Table 1 Demographics of study participants

\begin{tabular}{|c|c|c|c|c|}
\hline & $\begin{array}{l}\text { Sex } \\
M / F\end{array}$ & $\begin{array}{l}\text { Age }(S D) \\
\text { (years) }\end{array}$ & $\begin{array}{l}\text { Eye } \\
R / L\end{array}$ & $\begin{array}{l}\text { Retinopathy } \\
+/-\end{array}$ \\
\hline $\begin{array}{l}\text { HIV positive patients } \\
\text { Control patients } \\
\text { Significance }\end{array}$ & $\begin{array}{l}21 / 2 \\
21 / 2 \\
-\end{array}$ & $\begin{array}{l}35.9(7.48) \\
37.0(8.24) \\
p=0.642\end{array}$ & $\begin{array}{l}17 / 6 \\
15 / 8 \\
-\end{array}$ & $\begin{array}{l}14 / 9 \\
-\end{array}$ \\
\hline \multicolumn{5}{|c|}{$\begin{array}{l}\text { * Three patients had CMV retinitis in the contralateral eye. } \\
\text { Table } 2 \text { Arteriovenous passage time (AVP) in all HIV } \\
\text { positive patients and control subjects }\end{array}$} \\
\hline & & Number & \multicolumn{2}{|c|}{$A V P(S D)$ (seconds) } \\
\hline $\begin{array}{l}\text { HIV positive patients } \\
\text { Control subjects } \\
\text { Significance }\end{array}$ & & $\begin{array}{l}17 \\
18\end{array}$ & $\begin{array}{l}1.42(0 \\
1.51(0 \\
p=0.60\end{array}$ & $\begin{array}{l}.55) \\
0.48)\end{array}$ \\
\hline
\end{tabular}

Table 3 Arteriovenous passage time (AVP) in HIV positive patients, excluding three CMV retinitis patients, and control subjects

\begin{tabular}{lll}
\hline & Number & AVP (SD) (seconds) \\
\hline HIV positive patients & 14 & $1.37(0.47)$ \\
Control subjects & 18 & $1.51(0.48)$ \\
Significance & & $\mathrm{p}=0.415$ \\
\hline
\end{tabular}

interval from the date of diagnosis of HIV infection to the day of study was 4.4 years (range 9 months to 9.5 years). Fifteen patients had either documented systemic opportunistic infections or neoplasms, including three patients who had CMV retinitis in the contralateral eye. Five other patients had CD4+ T lymphocyte counts of $<200$ cells $\times 10^{6} / 1$ within 2 weeks of study. The remaining three patients did not have CD4+ T lymphocyte counts performed at the time of the study. All study patients and control subjects had Snellen visual acuities of $20 / 20$ or better in the study eye. Nine study patients (39\%) showed clinical evidence of HIV related retinopathy, including cotton wool spots, retinal haemorrhages, and/or microaneurysms at the time of examination. An additional five patients were found to have microvascular changes consistent with HIV related retinopathy only after their angiograms were reviewed. The total number of patients, therefore, who had either clinical or angiographic evidence of HIV related retinopathy was $14(60.9 \%)$ (Table 1$)$.

Video fluorescein angiography with the SLO was performed in all 23 patients. However, we were not able to measure AVP in six patients and CFV in three patients because of poor image quality. AVP was measured in 17 patients (10 had retinopathy) and results were compared with 18 control subjects (Table 2). There was no significant statistical difference between the two groups $(p=0.600)$; the difference remained insignificant when the three patients with CMV retinitis were excluded $(p=0.415)$ (Table 3). One way ANOVA analysis also revealed no significant statistical difference between the subgroups $\left(F_{(2,32)}=0.16\right.$, $\mathrm{p}=0.85)$. The CFV in 20 patients (12 had retinopathy) and 20 age-matched control subjects showed a significant reduction in the HIV positive patients $(p=0.013)$ (Table 4$)$; this relation remained after excluding the three CMV 
Table 4 Perifoveal capillary blood flow velocity (CFV) and homogeneity index $(C V(v))$ in all HIV positive patients and control subjects

\begin{tabular}{|c|c|c|c|}
\hline & Number & $\begin{array}{l}C F V(S D) \\
(\mathrm{mm} / \mathrm{s})\end{array}$ & $\begin{array}{l}C V(v)(S D) \\
(\%)\end{array}$ \\
\hline $\begin{array}{l}\text { HIV positive patients } \\
\text { Control subjects } \\
\text { Significance }\end{array}$ & $\begin{array}{l}20 \\
20\end{array}$ & $\begin{array}{l}2.43(0.29) \\
2.66(0.26) \\
p=0.013\end{array}$ & $\begin{array}{l}14.29(3.45) \\
14.79(6.21) \\
p=0.755\end{array}$ \\
\hline
\end{tabular}

Table 5 Perifoveal capillary blood flow velocity (CFV) and homogeneity index $(C V(v))$ in HIV positive patients, excluding three CMV retinitis patients, and control subjects

\begin{tabular}{|c|c|c|c|}
\hline & Number & $\begin{array}{l}C F V(S D) \\
(\mathrm{mm} / \mathrm{s})\end{array}$ & $\begin{array}{l}C V(v)(S D) \\
(\%)\end{array}$ \\
\hline $\begin{array}{l}\text { HIV positive patients } \\
\text { Control subjects } \\
\text { Significance }\end{array}$ & $\begin{array}{l}17 \\
20\end{array}$ & $\begin{array}{l}2.46(0.29) \\
2.66(0.26) \\
p=0.036\end{array}$ & $\begin{array}{l}14.29(3.46) \\
14.79(6.21) \\
p=0.769\end{array}$ \\
\hline
\end{tabular}

retinitis patients $(p=0.036)$ (Table 5$)$. One way ANOVA analysis showed a significant statistical difference between the subgroups $\left(F_{(2,38)}\right.$ $=3.42, p=0.043)$. Multiple comparisons were further made utilising the Tukey method. There was no significant difference between patients with HIV related retinopathy $(n=12)$ and those without retinopathy $(n=8)(q=0.82$, $\mathrm{p}>0.10$ ). Although a significant difference between patients with HIV related retinopathy and normal control subjects was found $(q=3.69, p<0.05)$, no difference was noted between patients without retinopathy and normal control subjects $(q=2.32, p>0.05)$. The coefficent of variation of the capillary blood flow velocities (homogeneity index) showed no significant difference between HIV positive patients and control subjects.

\section{Discussion}

Cotton wool spots are the most frequently encountered ocular manifestation in patients infected with HIV and have been reported to occur in up to $70 \%$ of AIDS patients. ${ }^{2-4}$ The constellation of cotton wool spots, intraretinal haemorrhages, and microaneurysms in the appropriate clinical context is ofter referred to as HIV related retinopathy. These clinical findings have also been observed in many other diseases, including diabetic retinopathy, hypertensive retinopathy, and in patients with systemic lupus erythematosus. ${ }^{1-21}$ It is believed that these lesions, when associated with HIV infection, similarly represent a microvasculopathy,,$^{2-6}$ and that they may be associated with more severe immunosuppression and a declining CD4+ count. ${ }^{42}$

The exact pathogenesis of these lesions is not known. Direct infection of the arteriolar endothelial cells by HIV has been implicated..$^{9-11}$ This view has been challenged by Faber and associates. ${ }^{23}$ Using immunohistochemical staining for CMV and HIV antigens along with trypsin digest preparations of the retinal vasculature, these workers suggested that the damage to the retinal endothelium that results in ischaemia manifested clinically by cotton wool spots was probably not caused by direct retinal endothelial cell infection by
$\mathrm{HIV}^{23}$ Other investigators also failed to isolate any organisms in association with the lesions of HIV related retinopathy. ${ }^{124781324}$

Some investigators point to an alteration of haemodynamics as the cause of HIV related retinopathy, since it shares many findings in common with other well described retinal vascular diseases such as diabetic and hypertensive retinopathy. ${ }^{23}$ 5-7 25 It has been hypothesised that, in the latter, hypoxia related to abnormal blood flow induces microangiopathic changes in vessels. ${ }^{26}{ }^{27}$ When studied by standard retinal fluorescein angiography, subjects with HIV related retinopathy demonstrated microaneurysms and telangiectasis primarily in the posterior pole, ${ }^{5}$ as well as areas of capillary non-perfusion in the perifoveal area. ${ }^{2}{ }^{5-7}$ Ultrastructural studies have demonstrated degeneration and loss of pericytes, swollen endothelial cells, thickened basal laminae, and narrowed capillary lumina, a picture which has a striking similarity to diabetic retinopathy. $^{25} 25$ Furthermore, haemorheological abnormalities in patients with HIV infection have also been noted. Engstrom and associates reported an increase in plasma viscosity and quantitative IgG levels in most of their patients. ${ }^{14}$ They also noted that the severity of conjunctival microvascular changes was associated with increased fibrinogen levels and elevated zeta sedimentation ratios. ${ }^{14}$ Increased circulating immune complexes have been detected in patients with HIV infection, ${ }^{6} 1228$ and a dynamic mechanism linking deposition of circulating immune complexes near the cotton wool spots in arteriolar walls to ischaemia has also been proposed. ${ }^{213}$ Further, reduced cerebral blood flow has been found to be related to the degree of retinal microvasculopathy. ${ }^{15}$ Finally, HIV infected patients have been shown to develop progressive clotting abnormalities. ${ }^{29}$ These findings all point to direct disturbances of haematological factors or to an alteration of haemodynamics which then affects the delivery of oxygen at the capillary level.

The availability of the SLO allows investigation of the retinal circulation in a quantitative manner in patients infected with HIV. It offers many advantages over previous techniques of observing, recording, and analysing retinal images. When combined with digital image analysis, it allows direct objective measurement of retinal blood flow, as has been demonstrated in a study of diabetic patients. ${ }^{16} \mathrm{We}$ applied this technique in our current study of HIV positive patients, and measured both the macrocirculation (AVP) and the microcirculation (CFV). Our results showed no significant difference in the macrocirculation between HIV positive patients and normal subjects. There was, however, a significant decrease in perifoveal capillary blood flow velocity in HIV positive patients. Further analysis to compare subgroups of HIV positive patients revealed no significant difference in CFV between those who had retinopathy and those who had no retinopathy. Interestingly, when compared with control subjects, the retinopathy group showed a statistically significant reduction in CFV 
while the no retinopathy group did not. Though there was a reduction of CFV, perhaps the small number of patients (eight) who showed no retinopathy did not provide sufficient study power to detect a statistical significance.

Since the capillary blood flow velocity alone does not reflect the total blood flow volume in the retina, no conclusion regarding whole retinal perfusion can be drawn from our study. However, integration of our findings with those of others, including the study of diabetic patients previously mentioned, ${ }^{16}$ suggests that a decrease in CFV may trigger events leading to ischaemia, and that such an alteration of haemodynamics could indeed be the common initiating event in the pathogenesis of the microvasculopathy seen clinically in patients infected with HIV, as well as in those with other retinal microvascular angiopathies, such as diabetic and hypertensive retinopathy.

Angiographic study of the retina was more sensitive than our clinical examination in detecting occult microvascular changes in these patients, as demonstrated in five of our patients in whom the clinical examination failed to detect any retinopathy. The advantages of SLO angiography over conventional angiography make it a useful tool in detecting early subclinical microvasculopathy in HIV infected patients. Uncertainty of the scaling factor is the major source of errors in measuring blood flow velocities when using SLO angiography. Knowing the curvature of the cornea and the length of the optical axis can reduce the error. ${ }^{17}$ Poor image quality can also limit interpretation of results.

The findings from our study are limited by several factors. The lack of better control conditions, such as matching anaemia and neutropenia in HIV positive patients with the control subjects, could affect the data. In addition, our study patients are not a homogeneous group. Twenty of the 23 patients had either documented opportunistic infections or had CD4+ $T$ lymphocyte counts of $<200 \times 10^{6} / 1$, and therefore fulfilled the criteria for the diagnosis of AIDS according to the revised classification system established by the Centers for Disease Control. ${ }^{30}$ The AIDS classification status of the remaining three patients is uncertain since a CD4+ T lymphocyte count was not available at the time of study, although these patients did not have any opportunistic infections. Three of the 19 patients with AIDS had CMV retinitis in their contralateral eye. Although the study eye was clinically free of any infectious retinopathy, the effects of the presence of CMV systemically as well as those of systemic agents used to treat the CMV infection on the retinal circulation are not known. Certainly, cotton wool spots have been observed by several authors to precede the development of frank CMV retinitis. ${ }^{126}$ Indeed, damage of the retinal vascular endothelium directly by CMV infection has been postulated as another possible aetiology of the microvasculopathy seen in AIDS patients. ${ }^{31}{ }^{32}$ If this hypothesis is true, the variables of retinal circulation measured in our three CMV infected patients could possibly have been affected on this basis. However, statistical analysis of our results remained unchanged after the three CMV infected patients were excluded. In addition, a more recent study failed to find cytomegalic retinal endothelial cells or pericytes in AIDS patients with or without CMV retinitis, and retinal vascular changes occurred in the absence of CMV retinitis. ${ }^{25}$ These authors suggested that the vasculopathy may precede CMV retinitis, but that it is unlikely that direct CMV infection of the retinal capillaries causes primary vascular damage. ${ }^{25}$ Finally, 20 of our study patients were receiving antiretroviral agents at time of the study. Zidovudine suppresses the bone marrow and may induce anaemia. The effect of anaemia on retinal blood flow is not known, although Engstrom and associates found no significant relation between any measure of the severity of conjunctival microvasculopathy and zidovudine use in HIV infected patients. ${ }^{14}$

In conclusion, we found in a small group of HIV positive patients, most of whom had AIDS, a statistically significant reduction of perifoveal capillary blood flow velocity. The significance of this result as it relates to the pathogenesis of HIV related retinopathy during the course of HIV infection is uncertain. Further investigation is needed to examine the relation between changes in the retinal circulation and the alteration of other haematological factors in different stages of HIV infection, and among subgroups of patients with HIV infection, such as those with and without opportunistic retinal infection.

Presented in part at ARVO, May 1994, Sarasota, FL, USA.

This study was supported in part by an unrestricted grant from Research to Prevent Blindness, Inc, New York, USA and from Research to Prevent

1 Palestine AG, Rodrigues MM, Macher AM, Chan CC, Lane HC, Fauci AS, et al. Ophthalmic involvement in acquired immunodeficiency syndrome. Ophthalmology 1984;91: immunodef

2 Pepose JS, Holland GN, Nestor MS, Cochran AJ, Foos RY. Acquired immune deficiency syndrome. Pathogenic mechanisms of ocular disease. Ophthalmology 1985;92: 472-84.

3 Jabs DA, Green WR, Fox R, Polk BF, Bartlett JG. Ocular manifestations of acquired immune deficiency syndrome. Ophthalmology 1989;96:1092-9.

4 Freeman WR Chen A, Henderly DE, Levine AM, Luttrull JK, Urrea PT, et al. Prevalence and significance of acquired immunodeficiency syndrome-related retinal microvasculimmunodeficiency syndrome-related retinal

5 Newson DA, Green WR, Miller ED, Kiessling LA, Morgan $\mathrm{B}$, et al. Microvascular aspects of acquired immune deficiency syndrome retinopathy. Am $\mathcal{f}$ Ophthalmol 1984; 98:590-601.

6 Holland GN, Pepose JS, Pettit TH, Gottlieb MS, Yee RD, Foos RY. Acquired immune deficiency syndrome. Ocular manifestations. Ophthalmology 1983;90:859-73.

7 Freeman WR, Lerner CW, Mines JA, Lash RS, Nadel AJ, Starr MD, et al. A prospective study of the ophthalmologic findings in the acquired immune deficiency syndrome. $\mathrm{Am}$ findings in the acquired immune

8 Freeman WR, O'Connor GR. Acquired immune deficiency syndrome retinopathy, pneumocystis, and cotton-wool syndrome retinopathy, pneumocystis,
spots. Am f Ophthalmol 1984;98:235-7.

9 Pomerantz RJ, Kuritzkes DR, de la Monte SM, Rota TR, Baker AS, Albert D, et al. Infection of the retina by human immunodeficiency virus type I. $N$ Engl f Med 1987;317: 1643-7.

10 Cantill HL, Henry K, Jackson B, Erice A, Ussery FM, Balfour Jr HH. Recovery of human immunodeficiency virus from ocular tissues in patients with acquired immune deficiency syndrome. Ophthalmology 1988;95:1458-62.

11 Skolnik PR, Pomerantz RJ, de la Monte SM, Lee SF, Hsiung GD, Foos RY, et al. Dual infection of retina with human immunodeficiency virus type I and cytomegalovirus. Am $\mathcal{F}$ Ophthalmol 1989;107:361-72.

12 Holland GN, Gottlieb MS, Yee RD, Schanker HM, Pettit TH. Ocular disorders associated with a new severe 
acquired cellular immunodeficiency syndrome. $A m \mathcal{f} O p h$ thalmol 1982;93:393-402.

13 Pepose JS, Nestor MS, Holland GN, Cochran AJ, Foos RY An analysis of retinal cotton-wool spots and cytomegalovirus retinitis in the acquired immunodeficiency syndrome. Am f Ophthalmol 1983;95:118-20.

14 Engstrom RE, Holland GN, Hardy WD, Meiselman HJ. Hemorheologic abnormalities in patients with human Hemorheologic abnormalities in patients with human crovasculopathy. Am $₹$ Ophthalmol 1990;109:153-61.

15 Geier SA, Schielke E, Klauss V, Muller A, Einhaupi KM Goebel FD, et al. Retinal microvasculopathy and reduced cerebral blood flow in patients with acquired immunodeficiency syndrome. Am $\mathcal{F}$ Ophthalmol 1992;113:100-1.

16 Arend $O$, Wolf $S$, Jung F, Bertam B, Postgens $H$, Toonen $H$, et al. Retinal microcirculation in patients with diabetes mellitus: dynamic and morphological analysis of perifoveal capillary network. Br $\mathcal{F}$ Ophthalmol 1991;75:514-8.

17 Littmann H. Zur Bestimmung der wahren Grobe eines Objekte auf dem Hintergrund eines lebenden Auges. Klin Monatsbl Augenheilkd 1988;192:66-7.

18 Brown GC, Brown MM, Hiller T, Fischer D, Benson WE Magargal LE. Cotton-wool spots. Retina 1985;5:206-14.

Magargal LE. Cotton-wool spots. Retina 1985;5:206-14.
Chihara E. Pathogenesis of cotton-wool patches. A clinical study. Fpn f Ophthalmol 1983;27:397-403.

20 Aronson AJ, Ordonez NG, Diddie KR, Ernest T. Immunecomplex deposition in the eye in systemic lupus erythematosus. Arch Intern Med 1979;139:1312-3.

21 Yanoff M, Fine BS. Ocular pathology. 2nd ed. Philadelphia: Harper and Row, 1982:486.

22 Kuppermann BD, Petty JG, Richman DD, Mathews WC Fullerton SC, Rickman LS, et al. Correlation between CD4+ counts and prevalence of cytomegalovirus retinitis and human immunodeficiency virus-related noninfectious and human immunodeficiency virus-related noninfectious ciency syndrome. Am $f$ Ophthalmol 1993;115:575-82.
23 Faber DW, Wiley CA, Lynn GB, Gross JG, Freeman WR. Role of HIV and CMV in the pathogenesis of retinitis and retinal vasculopathy in AIDS patients. Invest Ophthalmo $V$ is Sci 1992;33:2345-53.

24 Holland GN, Gottlieb MS, Foos RY. Retinal cotton-wool patches in acquired immunodeficiency syndrome. $N$ Engl $\mathcal{F}$ patches in acquired imm $1982 ; 307: 1704-5$.

25 Glasgow BJ, Weisberger AK. A quantitative and cartographic study of retinal microvasculopathy in acquired immunodeficiency syndrome. Am $\mathcal{F}$ Ophthalmol 1994;118: 46-56.

26 Ditzel J. Changes in red cell oxygen release capacity in diabetes mellitus. Fed Proc 1979;38:2484-8.

27 Yanoff M. Ocular pathology of diabetes mellitus. Am f Ophthalmol 1969;67:21-38.

28 Euler $\mathrm{HH}$, Kern $\mathrm{P}$, Loffler $\mathrm{H}$, Dietrich $M$. Precipitable immune complexes in healthy homosexual men, acquired immune deficiency syndrome and the related lymphaden opathy syndrome. Clin Exp Immunol 1985;59:267-75.

29 Deutsch TA, Goldstick TK, Thomas CH, de Groot MC, Matz DV. HIV-infected patients develop progressive clotting abnormalities. Invest Ophthalmol Vis Sci 1993;34: 1057.

30 Centers for Disease Control. Revised classification system for HIV infection and expanded surveillance case definition for AIDS among adolescents and adult. MMWR 1992;RR-17:1-19.

31 Grefte A, van der Giessen $M$, van Son W, The TH Circulating cytomegalovirus (CMV)-infected endothelial cells in patients with an active cytomegalovirus infection. $\mathscr{f}$ Infect Dis 1993;167:270-7.

32 Schmitt-Graff A, Neuen-Jacob E, Rettig B, Sundmacher R. Evidence for cytomegalovirus and human immunodefiEvidence for cytomegalovirus and human immunodef-
ciency virus infection of the retina in AIDS. Virchows Arch A Pathol Anat Histopathol 1990;416:249-53. 